\title{
Automatic Surface Size Distribution Observation of Graded Sand Bed Based on Digital Image Analysis
}

\author{
Zhijing Li*, Jun Wang, Zhongwu Jin and Yinjun Zhou \\ Changjiang River Scientific Research Institute, Wuhan 430010, China \\ ${ }^{*}$ Corresponding author
}

\begin{abstract}
Traditional method commonly used in bulk sampling and sieve analyses is inevitablely involved the bed surface excavation and destroy the original bed size distribution. In this work, an automatic surface size distribution observation method based on digital image analysis without involving the bed surface excavation is proposed and the validity of this method is tested by an experimental case. The surface size distribution results from this method are compared with the traditional volume-by-weight method, and it is shown that a conservative estimate of the error in measuring bed surface composition for this method is considerably smaller.
\end{abstract}

Keywords-graded sediment; digital image analysis; surface size distribution; automatic recognition

\section{INTRODUCTION}

The mechanics of sediment transport in alluvial rivers is an important issue in fluvial hydraulics and morphodynamics. Since mid-18th century, this issue has been a hot subject of study, and a lot of inspiring findings put this subject to a new height [1-4]. However, nature will not be so easy for us to understand clearly, and pose a series of impediments to the refinement of further study. Among these obstacles, the transport of non-uniform sediment is absolutely one of the most challenging issues because of the unsteady and random characteristics in its physical process.

Previous researches in the field of sediment transport are mostly focus on the transport of uniform sediments, numerous formulae and mathematical models have been proposed for sediment transport stressing a different aspect of sediment characteristics. Yet, these formulae and models were verified by experimental data with uniform or nearly uniform sediment only, and can only be used as a qualitative estimation for real rivers. The transport mechanism of non-uniform sediment transport is different to that of uniform sediment due to the exchange of different particle size in the suspension and bed material [5-7]. For example, the settling velocity does not vary with the exchange between the suspended and bed material for uniform sediment while the exchange between the suspended and bed material changes the size distributions of suspended and bed material under non-uniform sediment transport. As a result, the previous achievements in the study of uniform sediment transport can not be directly applied on the nonuniform sediment transport, and employing the non-uniformity of sediment in the simulation of sediment transport is needed.

During the last several decades, a number of experiments have been performed and lots of numerical models have been proposed for the investigation of sediment transport with a range of sediment sizes including those of Proffitt and Sutherland (1983), Dietrich et al. (1989), Paola et al. (1992), Parker and Wilcock (1993), Wilcock and McArdell (1993), Lu and Zhang (1993), Yen and Lee (1995), Willetts et al. (1998), Wu (2004), Fischer-Antze et al. (2009), Yang et al. (2010), Viparelli et al. (2010a, b) [8-20]. To a certain extent, these meaningful studies have revealed the mechanics of nonuniform sediment transport.

However, due to the complex characteristics, the understanding of some fundamental issues is still far from sufficient. For field graded sediment transport observation, selecting sand sample of the riverbed to be analyzed is necessary to make the quantitative description of the composition distribution. This requires a sediment sample sieving process, involving a series of subjective influencing factors: such as the specific location of the selected sample, and a selection of measurement method and the like. Different researchers to the same segment may be get completely different results due to the research methods used. Also, in the case of experiment study, sediment sample sieving method is an important component of the study, as the sieving results have a direct impact on the entire experimental work. Thus, the study on the sediment sieving methods is of great scientific significance. This study presents an automatic surface size distribution observation method for graded sand bed based on digital image analysis. It may get the surface bed size distribution in the course of the experiment on the testing process through sand bed image analysis and does not produce a disturbance of the conditions, which enables the real time observation and analysis of surface bed material composition.

\section{METHOD}

\section{A. Calculation of Grain-size Distributions and Statistics}

Grain-size distributions and statistics may be calculated and presented in a variety of different ways. When comparing grain-size information it is essential to ensure that like is compared with like. Generally, grain-size distributions are presented as cumulative curves showing the proportion of grains finer or coarser than a given size. Grid-by-number distributions are conventionally generated by sampling grains on a regular grid laid across the surface to be sampled (e.g. a Wolman grid sample). In this type of sample, the probability of sampling a particular grain is proportional to its area. Each grain is weighted based on its area before calculating the distribution parameters. Although it produces results that are equivalent to a grid-based sample, the method uses every grain in the sampling area and it is therefore possible to derive a 
sample from a much smaller area than would be possible using a conventional grid-based sampling method (in which only a small proportion of the grains in the sampling area is actually sampled).

The conventional method of calculating percentiles (used when grain-size information is only available for size classes, such as for sieve-derived data), is to obtain the percentiles at each size-class boundary and apply a linear interpolation to obtain intermediate percentiles.

Graphical statistics are based on percentiles of the grainsize distribution. Such percentiles were traditionally determined manually from a hand-drawn cumulative grain-size distribution curve produced from the number of grains in individual sieve-size classes. Graphical statistics have the advantage that they are not sensitive to the tails of the distribution (which are commonly relatively poorly constrained).

Moment statistics are based on the entire grain-size distribution and are particularly simple to calculate using a computer without the need to obtain grain-size percentiles. Their advantage over graphical statistics is that they utilise the entire grain-size distribution. The corollary is that they are inappropriate where the tails of the distribution are inadequately specified. Moment statistics are conventionally calculated from sieve-derived data based on the proportion of grains in each sieve class. Using this approach, the number of classes used affects the values obtained.

\section{B. Measurement Procedures}

Step 1: The setting of the imaging device, imaging device by the walk - on of the bracket that is fixed to the test over the sink, that is perpendicular to the surface of the bed, next to the image pickup apparatus equipped with the LED light source.

Step 2: Refer to the following formula to adjust the area of bed sand area,

$$
A=\left(\frac{g \sqrt{P}}{23,000}\right)^{2}
$$

where $A$ is the area of sand bed, $g$ is the smallest particle size of bed sediment, and $P$ is the pixel of the image collected by the camera equipment.

Step 3: Digital image acquisition, LED light source bed surface, camera equipment on riverbed shooting digital image acquisition, camera and image analysis system is connected via a data line, real-time image to digital image analysis system for transmission (Figure 1).

Step 4: The image analysis system is used to analyze the digital image, and the distribution data of the bed surface is output. The image analysis system would automatically determination of the color RGB value interval corresponding to the sediment particle size; cropping image to remove part of the sink wall; making image distortion correction (Figure 2); reading image pixel information; putting a grid on the image; counting the total number of statistical grid nodes; saving on each grid node on the image color RGB value; obtaining the proportion of each color that is the size of the sampling area; and finally get the distribution of surface sediment distribution data.

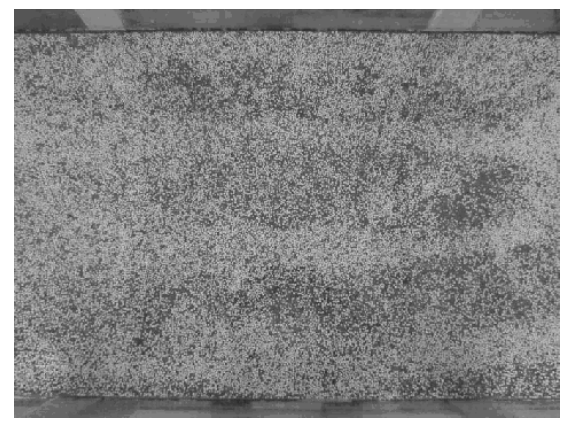

FIGURE I. ORIGINAL IMAGE BY CAMERA OVER THE FLUME.

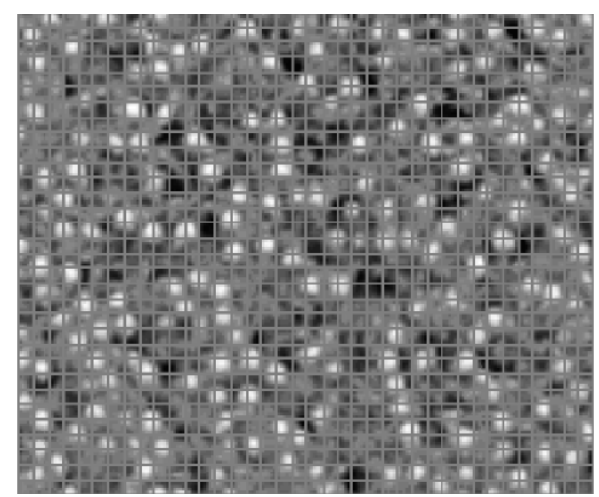

FIGURE II. IMAGE PREPARING FOR AUTOMATICAL ANALYSING (AFTER CUTTING AND GRIDING).

\section{EXPERIMENTAL CASE STUDY}

The experiments are conducted in two flumes with different size. The big flume is $80 \mathrm{~m}$ long, $1.2 \mathrm{~m}$ wide and $0.8 \mathrm{~m}$ deep, while the small flume is $10 \mathrm{~m}$ long, $0.5 \mathrm{~m}$ wide and $0.5 \mathrm{~m}$ deep. A $20 \mathrm{~cm}$ layer of sediment is laid in both flumes with the length of $12 \mathrm{~m}$ for big flume and $6 \mathrm{~m}$ for small flume, and a certain length of fixed bed is employed before the sediment bed. The initial fixed bed and sediment bed slope is set to be 0.003 . The flume has clear sidewalls, and is mounted with camera, automatic water-level probes and automatic terrain monitor, and a computer is deployed to process the stage and bed elevation data transmitted from the probes. By the end of the sediment bed, $0.05 \mathrm{~m}$ of the bed is made rigid to prevent local scour, and then a replaceable sediment trap is equipped for collection of the transported material. An electromagnetic flow meter is emplaced at the inlet of the flume to determine the inflow discharge, and the flow regime can be controlled by means of a tailgate at the outlet end of the flume. The design of two flumes with different size was used to capture any scale effects which should occur due to, for example, sediment viscosity.

Two fractions of well sorted approximate uniform bed sediments are prepared for the experimental runs. The big size fraction called Sample A is in the $2.0 \mathrm{~mm}-4.0 \mathrm{~mm}$ range, particle appearance is spherical or elliptical, and particle material is ceramic with density of $2389 \mathrm{~kg} / \mathrm{m}^{3}$. The small size 
fraction called Sample B is in the $0.1 \mathrm{~mm}-2.0 \mathrm{~mm}$ range which is sieved by natural sand with density of $2650 \mathrm{~kg} / \mathrm{m}^{3}$. By mixing Sample A and B according to the mass ratio of $1: 1$, we can get non-uniform Sample C. Particularly, Sample A is painted with white color and Sample B has a yellow color, this allows the employment of photographic method for the measurement of bed surface size distribution.

At the end of each run of the experiments, the bed surface composition was measured by two methods. The first was the traditional volume-by-weight method commonly used in bulk sampling and sieve analyses, which involved the bed surface excavation. The second was the proposed automatic surface size distribution observation method based on digital image analysis. This was accomplished by projecting photographs of the bed onto a grid, and tallying the grain color (hence sand or gravel) falling on the grid. Each photograph covered a bed section $1 \mathrm{~m}$ wide and $1.2 \mathrm{~m}$ long, while the remaining $10 \mathrm{~cm}$ on each side of the flume was not photographed. Ten adjacent photographs provided continuous downstream coverage of the $12 \mathrm{~m}$ long working section of the channel. For each photograph, $500 \times 600$ points were counted and analyzed by computer, the cross-stream and downstream separations between grid points were $2 \mathrm{~mm}$, and the diagonal separation between grid points was $2.8 \mathrm{~mm}$. This spacing is smaller than the largest size on the bed.

To investigate how the bed surface composition changes in time during the course of the experiments, the bed surface in a particular section of the channel, i.e., $2.4<x<3.6 \mathrm{~m}$, was photographed every 1 hour and the gravel and sand proportions were determined by the grid-by-number method. This complements the measurement of bed surface composition at the end of each run of the experiments. The photographs were taken through the flowing water, without shutting the flow off and disturbing the experiment. In principle, the photographs so taken may capture the moving bed load sediment particles, in addition to those the bed surface. Yet, it is hard to distinguish these moving particles from those on the bed surface, though moving particles were scarce by visual observation. Thus uncertainty is inevitable concerning the observed bed surface size distribution attained by this method.

To evaluate the bed surface composition sampled for cases of graded sediment transport, $F_{i}$ is introduced to represent the proportion of sand $\left(F_{s}\right)$ or gravel $\left(F_{g}\right)$ in the bed surface. Fig. 8 shows the variation of the bed surface composition of Run C4. During the degrading process, the bed surface coarsened considerably (Figure 3). Longitudinally, the bed coarsening extended to the whole sediment bed section of the channel within 7 hours and the final bed coarsened roughly uniformly as compared to the initial bed (Figure 3). From Figure 3 we can see that a conservative estimate of the error in measuring bed surface composition for this method was $\pm 30 \%$, and the actual error should be considerably smaller. Temporally, the bed within subsection $2.4<x<3.6 \mathrm{~m}$ coarsened in time (Figure 4). The longitudinally uniform coarsening renders it appropriate to evaluate the whole-section averaged coarsening as function of flow discharge. In this sense, the bed surface of the whole sediment bed was significantly coarsened, as the percent gravel
$F_{g}$ and median size $d_{50}$ of the final bed are obviously larger than those of the initial bed (Figure 4).

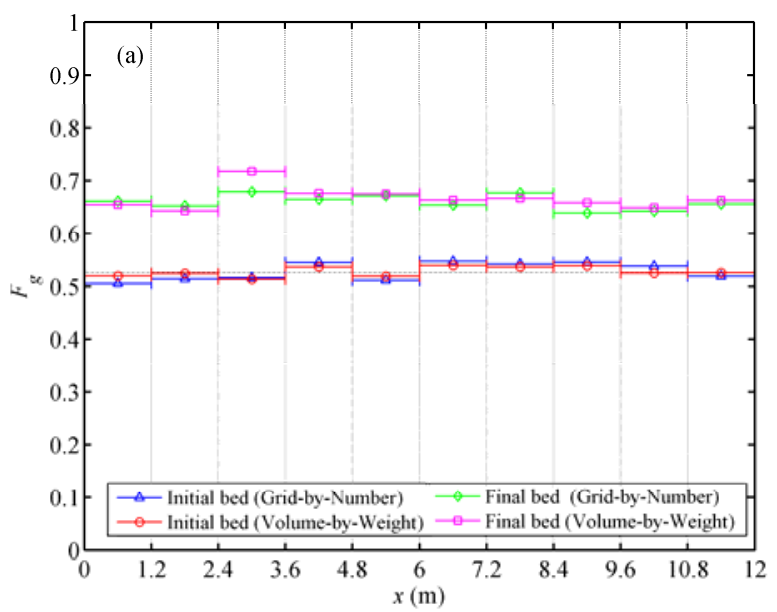

FIGURE III. BED SURFACE COMPOSITION OF THE EXPERIMENTAL CASE: PERCENT (VOLUME) GRAVEL ON THE INITIAL AND FINAL BED SURFACE

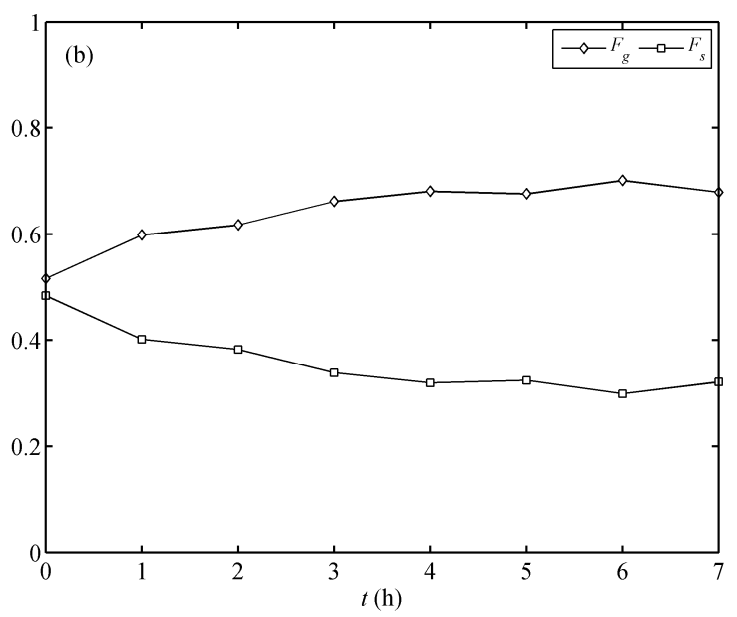

FIGURE IV. VARIATION OF PERCENT (VOLUME) GRAVEL $\left(F_{g}\right)$

AND SAND $\left(F_{s}\right)$ ON THE BED SURFACE WITHIN SUBSECTION $2.4<X<3.6 \mathrm{M}$

\section{CONCLUSIONS}

An automatic surface size distribution observation method for graded sand bed based on digital image analysis and without involving the bed surface excavation is proposed and tested by an experimental case. The surface size distribution results from this method are compared with the traditional volume-by-weight method which is commonly used in bulk sampling and sieve analyses. It is noted that a conservative estimate of the error in measuring bed surface composition for this method was $\pm 30 \%$, and the actual error should be considerably smaller. 


\section{ACKNOWLEDGMENT}

The research is funded by Natural Science Foundation of China (Grants No. 51609013, 51579014 and 51339001), the National Key Research and Development Program of China (2016YFC0402302), and the Non-profit Industry Financial Program of MWR (201501042).

\section{REFERENCES}

[1] Einstein, H. A. (1950). "The bed-load function for sediment transportation in open channel flows.” Water Resources Building, 43.

[2] Zhang, R., Xie, J. (1993). Sedimentation research in China-systematic selections. China Water and Power Press, Beijing.

[3] Chien, N., and Wan, Z. (1999). Mechanics of sediment transport. American Society of Civil Engineers, Reston, VA (US).

[4] Wu, W. M. (2007). Computational river dynamics. Taylor \& Francis, London.

[5] Galappatti, G., and Vreugdenhil, C. B. (1985). “A depth-integrated model for suspended sediment transport." Journal of Hydraulic Research, 23(4), 359-377.

[6] Armanini, A., and Di Silvio, G. (1988). "A one-dimensional model for the transport of a sediment mixture in non-equilibrium conditions." Journal of Hydraulic Research, 26(3), 275-292.

[7] Holly, F. M. J., and Rahuel, J. L. (1990). "New numerical/physical framework for mobile-bed modelling. Part 1 . Numerical and physical principles.” Journal of Hydraulic Research, 28(4), 401-416.

[8] Proffitt, G. T., Sutherland, A. J. (1983). “Transport of non-uniform sediments.” Journal of Hydraulic Research, 21(1), 33-43.

[9] Dietrich, W. E., Kirchner, J. W., Ikeda, H., Iseya, F. (1989). “Sediment supply and the development of the coarse surface layer in gravel-bedded rivers." Nature, 340, 215-217.

[10] Paola, C., Parker, G., Seal, R., Sinha, S. K., Southard, J. B., Wilcock, P. R. (1992). "Downstream Fining by Selective Deposition in a Laboratory Flume.” Science, 258(5089), 1757-1760.

[11] Parker, G., Kilingeman, P. C. and Mclean, D. G. (1982). "Bed load and size distribution in paved gravel-bed streams”. Journal of Hydraulic Division, ASCE, 108(4), 544-571.

[12] Wilcock, P. R., McArdell, B. W. (1993). "Surface-based fractional transport rates Mobilization thresholds and partial transport of a sandgravel sediment.” Water Resources Research, 29(4), 1297-1312.

[13] Lu, Y. J., Zhang, H. Q. (1993). "Experiment study on armoring mechanism of bed material with wide size-distribution by clear water." Journal of Sediment Research, 1, 69-77 (in Chinese).

[14] Yen, C., Lee, K. (1995). "Bed topography and sediment sorting in channel bend with unsteady flow.” Journal of Hydraulic Engineering, 121(8), 591-599.

[15] Willetts, B. B., Pender, G., Mcewan, I. K. (1998). "Experiments on the transport of graded sediment.” Proceedings of the Institution of Civil Engineers. Water, maritime and energy, 130, 217-225.

[16] Wu, W. M. (2004). "Depth-averaged two-dimensional numerical modeling of unsteady flow and nonuniform sediment transport in open channels.” Journal of Hydraulic Engineering, 130, 1013.

[17] Fischer-Antze, T., Rüther, N., Olsen, N., and Gutknecht, D. (2009). "Three-dimensional (3D) modeling of non-uniform sediment transport in a channel bend with unsteady flow.” Journal of Hydraulic Research, 47(5), 670-675.

[18] Yang, F. G.., Liu, X. N., Cao, S. Y., Huang, E. (2010). "Bed load transport rates during scouring and armoring processes." Journal of Mountain Science, 7, 215-225.

[19] Viparelli, E., Haydel, R., Salvaro, M., Wilcock, P., and Parker, G. (2010) "River morphodynamics with creation/consumption of grain size stratigraphy 1: laboratory experiments.” Journal of Hydraulic Research, 48(6), 715-726.

[20] Viparelli, E., Sequeiros, O., Cantelli, A., Wilcock, P., and Parker, G. (2010). "River morphodynamics with creation/consumption of grain size stratigraphy 2: numerical model.” Journal of Hydraulic Research, 48(6), 727-741. 